\title{
A Review on Bovine Brucellosis: Epidemiology, Diagnosis and Control Options
}

\author{
Ashenafi Kiros ${ }^{1}$; Hagos Asgedom ${ }^{1}$ Reta Duguma Abdi $^{2}$ \\ ${ }^{1}$ NAHDIC (National Animal Health Diagnostic and Investigation Centre), Sebeta, Ethiopia. \\ ${ }^{2}$ Addis Ababa University, College of Veterinary Medicine and Agriculture, Debreziet, Ethiopia.
}

\begin{abstract}
Brucellosis is economically important zonootic bacterial disease caused by genus Brucella. It contains different species such as B. abortus, B.melitensis, B.suis, B.ovis, B.canis, B.neotome, B. microti that affect terrestrial animals and B. ceti and B. pinnipedialis affect marine mammals. The first three species are called classical Brucella. Three of them are differentiated into biovars. Brucella have no classic virulence genes encoding capsules, plasmids, pili or exotoxins contributing to the persistence in the host and multiplication within phagocytic cell. Brucellosis occurs worldwide, except a few countries that have been successfully eradicated. The aborted fetus, fetal membrane and uterine discharges are considered as the major source of infection. Brucellosis is mainly transmitted to animals by ingestion of contaminated feed and water, by contact with infected aborted fetus, fetal membrane and genital discharges, and by artificial insemination from infected bulls. The bacteria are preferentially localized mainly in the reproductive tract of pregnant animals and consequently cause abortion (late abortion), retained fetal membrane and infertility, where as orchitis and epididimitis are seen in males. Among the serological tests, RBPT for screening and CFT for confirmatory are routinely used in Ethiopia. Brucellosis remains one of the most common zonootic diseases worldwide with more than 50,000 human cases reported annually. It is mainly transmitted to humans through the consumption of unpasteurized dairy products, direct contact with infected animal parts. The disease also causes huge economic loses which arises from abortion culling of infected animal, hindering animal export trades of a country, treatment costs, time and costs allotted for research and eradication programs. Formulating effective control strategies are needed that includes surveillance to identify infected animals, prevention of transmission to non infected animals and removal of the reservoir to eliminate the source of infection. In addition, vaccination of susceptible animals is also important in areas where high prevalence of brucellosis exists.
\end{abstract}

Keywords: Brucellosis, Control, Diagnosis, Prevalence, Transmission, Zonoosis

\section{INTRODUCTION}

Brucellosis is a highly contagious, zoonotic and economically important bacterial disease of animals worldwide and it is considered by the Food and Agriculture Organisation (FAO), the World Health Organisation (WHO) and the Office International des Epizooties (OIE) as one of the most widespread zoonoses in the world (Schelling et al, 2003). The disease in cattle, usually caused by Brucella abortus and occasionally by Brucella melitensis and Brucella suis, is characterised by late term abortion, infertility and reduced milk production as a result of retained placenta and secondary endometritis and excretion of the organisms in uterine discharges and milk. Full-term calves may die soon after birth. In fully susceptible herds, abortion rates may vary from 30- 80\% (Anonymous, 2007).

In Africa, bovine brucellosis was first recorded in Zimbabwe (1906), Kenya (1914) and in Orange Free State of South Africa in the year 1915 (Chukuwu, 1985). However, still the epidemiology of the disease in livestock and humans as well as appropriate preventive measures are not well understood and such information is inadequate particularly in sub-Saharan Africa. The surveillance and control of brucellosis in this region is rarely implemented outside South Africa (McDermot et al., 2002). In dairy production, the disease is a major obstacle to the importation of high yielding breeds and represents a significant constraint to the improvement of milk production through cross breeding (Mustefa and Nicoletti, 1993). 
In Ethiopia, there is no documented information on how and when brucellosis was introduced and established. Even though, several serological surveys have showed bovine brucellosis is an endemic and widespread disease in urban, peri-urban, highland and lowland, extensive and intensive farming, smallholder farms and ranches of the country (Dinka and Chala, 2009). However, most of the studies on cattle brucellosis have been carried out in central and northern Ethiopia and do not provide an adequate epidemiological picture of the disease in different agro-ecological zones and livestock production systems of the country (Megersa et al., 2011).

The evidences of brucellosis in Ethiopian cattle have been serologically demonstrated by different authors. A high seroprevalence of brucellosis (22\%) has been reported in dairy herd of Cheffa state farm (Sintaro, 1994), while most of the studies suggested a low seroprevalence (below 5\%) in cattle under crop-livestock mixed farming (Berhe et al., 2007; Ibrahim et al., 2010). There is a scarcity of published literature on the status of cattle brucellosis in pastoral areas of the country where large population of cattle are reared. So far, a study carried out in east Showa zone of Ethiopia showed a relatively higher seroprevalence in pastoral than agro pastoral system (Dinka and Chala, 2009).

Generally, one of the highest priority diseases, both in sub-Saharan Africa and other regions of the developing world is brucellosis. The importance of brucellosis reflects its widespread distribution and its impacts on multiple animal species, including cattle, sheep, goats, pigs and humans. While the importance of brucellosis is widely assumed, the benefits of programs to control it, relative to their costs, need to be assessed. The important components of such an assessment are: (1) to understand the epidemiology of brucellosis in different livestock production systems, (2) to evaluate how different measures can reduce the transmission of brucellosis in these systems and (3) to estimate the benefits to costs of different brucellosis control strategies and how these compare to competing public-sector investments (Mc Dermot et al., 2002).

Therefore, the objectives of this seminar are:

- To review the epidemiology of the disease.

- To highlight gaps in the current knowledge regarding the diagnostic and control methods of brucellosis.

\section{BOVINE BRUCELLOSIS}

\section{1. Characteristics of Brucella}

Brucella species are facultative intracellular, gram negative, non-spore-forming and non-capsulated, partially acid-fast coccobacilli that lack capsules, endospores or native plasmids. They survive freezing and thawing but most disinfectants active against gram-negative bacteria kill Brucella. Pasturization effectively kills Brucella in milk. The bacterium is of $0.5-0.7 \mu$ in diameter and 0.6$1.5 \mu$ in length. They are oxidase, catalase and urease positive. Although Brucella species are described as non-motile, they carry all the genes except the chemotactic system necessary to assemble a functional flagellum (Fretin et al., 2005). They belong to the alpha-2 subdivision of the Proteobacteria, along with Ochrobactrum, Rhizobium, Rhodobacter, Agrobacterium, Bartonella, and Rickettsia (Yanagi and Yamasato, 1993).

Ten genome sequences representing five species of Brucella (B. melitensis, B. suis, B. abortus, B. ovis, and $B$. canis) are available and about 25 additional Brucella strains/species are being sequenced. The genomes of the members of Brucella are very similar in size and gene make up (Sriranganathan et al., 2009). Each species within the genus has an average genome size of approximately $3.29 \mathrm{Mb}$ and consists of two circular chromosomes, Chromosome I, is approximately on average $2.11 \mathrm{Mb}$ and Chromosome II is approximately1.18 Mb. The G + C content of all Brucella genome is $57.2 \%$ for Chromosome I and 57.3\% for Chromosome II (Halling et al., 2005).

Based on a comparison of 10 published Brucella genomes, what is striking are the shared anomalous regions found in both chromosomes consistent with horizontal gene transfer in spite of a predominantly intracellular life style. The Brucella have no classic virulence genes encoding capsules, plasmids, pili or exotoxins and compared to other bacterial pathogens relatively little is known about the factors contributing to the persistence in the host and multiplication within phagocytic cells. Also, many aspects of interaction between Brucella and its host remain unclear (Seleem et al., 2008). 


\section{2. Epidemology}

\section{2. 1. Global distribution}

The geographical distribution of brucellosis is constantly changing, with new foci emerging or reemerging. New foci of human brucellosis have emerged, particularly in central Asia, while the situation in certain countries of the Middle East is rapidly worsening (Pappas et al., 2006).

The disease occurs worldwide, except countries which include Australia, Canada, Cyprus, Denmark, Finland, Netherlands, New Zealand, Norway, Sweden and the United Kingdom which has eradicated. This is defined as the absence of any reported cases for at least five years. However, the Mediterranean Countries of Europe, Africa, Near East countries, India, Central Asia, Mexico, Central and South America are still not brucellosis free. Although in most countries brucellosis is a nationally notifiable disease and reportable to the local health authority, it is under reported and official numbers constitute only a fraction of true incidence of the disease (Robinson, 2003).

High prevalence (24.5\%) was reported from Sudan among African countries as indicated in Table 1. In Ethiopia a high seroprevalence of brucellosis (22\%) has been reported in dairy herd of Cheffa state farm (Sintaro, 1994), while most of the studies suggested a low seroprevalence (below 5\%) in cattle as summarized in Table 2 below.

Table 1. Sero-prevalence of bovine brucellosis in different production systems in some African and Asian countries.

\begin{tabular}{|c|c|c|c|c|c|c|}
\hline S/No. & Country & $\begin{array}{l}\text { No of } \\
\text { cattle }\end{array}$ & Prevalence & Test applied & Authors and years & $\begin{array}{l}\text { Type of } \\
\text { system }\end{array}$ \\
\hline 1 & Zambia & 1245 & 14.1 & $\begin{array}{l}\text { RBPT, } \\
\text { ELISA }\end{array}$ & Muma et a., 12007 & Extensive \\
\hline 2 & Kenya & 393 & 1 & c-ELISA & Kang'ethe et al.,2007 & $\begin{array}{ll}\text { Extensive } \quad \& \\
\text { Intensive. }\end{array}$ \\
\hline 3 & Zimbabwe & 1291 & 5.5 & $\begin{array}{l}\text { RBPT, } \\
\text { ELISA }\end{array}$ & Matope et al., 2010 & Intensive \\
\hline 4 & Sudan & 574 & 24.5 & $\begin{array}{l}\text { RBPT, } \\
\text { ELISA }\end{array}$ & Angara et al., 2010 & Intensive \\
\hline 5 & Pakistan & 200 & 3.0 & MRT, ELISA & Shafee et al., 2011 & Intensive \\
\hline 6 & Bangladish & 188 & 2.66 & RBPT, ELISA & Rahman et al., 2011 & Intensive \\
\hline 7 & Ghana & 224 & 21.9 & MRT, i-ELISA & Mensah et al., 2011 & Extensive \\
\hline
\end{tabular}

Table 2. Seroprevalence of bovine brucellosis in Ethiopia in different geographical areas under different production systems

\begin{tabular}{|c|c|c|c|c|c|c|}
\hline $\mathrm{S} / \mathrm{No}$ & Study area & $\begin{array}{l}\text { No of cattle } \\
\text { tested }\end{array}$ & prevalence & $\begin{array}{l}\text { Type of } \\
\text { test }\end{array}$ & $\begin{array}{l}\text { Authors and } \\
\text { years }\end{array}$ & Type of system \\
\hline 1 & Jimma zone & 1,813 & 0.61 & $\begin{array}{l}\text { RBPT, } \\
\text { SAT }\end{array}$ & Tolosa, 2004 & Extensive \& intensive \\
\hline 2 & Tigray & 1,951 & 1.49 & $\begin{array}{l}\text { RBPT, } \\
\text { SAT }\end{array}$ & Berhe, 2007 & Extensive \& intensive \\
\hline 3 & Bahr Dar & 1,944 & 4.63 & $\begin{array}{l}\text { RBPT, } \\
\text { SAT }\end{array}$ & $\begin{array}{l}\text { Hailemelekot, } \\
2005\end{array}$ & Extensive \& intensive \\
\hline 4 & $\begin{array}{l}\text { Cent. } \\
\text { Oromia }\end{array}$ & 1,238 & 2.99 & $\begin{array}{l}\text { RBPT, } \\
\text { SAT }\end{array}$ & Jegerfa, 2006 & Extensive \& intensive \\
\hline 5 & $\begin{array}{l}\text { AA } \\
\text { \&Suluta }\end{array}$ & 1,501 & 1.13 & $\begin{array}{l}\text { RBPT, } \\
\text { SAT }\end{array}$ & Tefera, 2006 & Extensive \& intensive \\
\hline 6 & Tigray & 1,968 & 4.9 & RBPT,SAT & Haileselassie, & Semi-intensive \\
\hline
\end{tabular}


Ashenafi Kiros et al.

\begin{tabular}{|c|c|c|c|c|c|c|}
\hline & & & & & 2008 & extensive \\
\hline 7 & East Shewa & 1,106 & 11.5 & RBPT & $\begin{array}{l}\text { Dinka \& Chala, } \\
2009\end{array}$ & $\begin{array}{l}\text { Pastoral } \quad \& \quad \text { agro- } \\
\text { pastoral }\end{array}$ \\
\hline 8 & $\begin{array}{l}\text { Sidama } \\
\text { zone }\end{array}$ & 1,627 & 1.66 & $\begin{array}{l}\text { RBPT, } \\
\text { SAT }\end{array}$ & $\begin{array}{l}\text { Asmare et a., } \\
2010\end{array}$ & Extensive \\
\hline 9 & Jijjiga & 435 & 1.38 & $\begin{array}{l}\text { RBPT, } \\
\text { SAT }\end{array}$ & $\begin{array}{l}\text { Degefu et al., } \\
2011\end{array}$ & Agro-pastorals \\
\hline 10 & $\begin{array}{l}\text { South\&East } \\
\text { Eth }\end{array}$ & 1,623 & 3.5 & $\begin{array}{l}\text { RBPT, } \\
\text { SAT }\end{array}$ & $\begin{array}{l}\text { Megersa et al., } \\
2011\end{array}$ & Extensive \\
\hline
\end{tabular}

Remark; AA - Addis Ababa

Eth- Ethiopia

\subsubsection{Host range and Brucella diversity}

The principal strain that infects cattle is $B$. abortus. Cattle can also become transiently infected by $B$. suis and more commonly by $B$. melitensis when they share pasture or facilities with infected pigs, goats and sheep. B. melitensis and B. suis can be transmitted by cow's milk and cause a serious public health threat (Acha and Szyfres, 2003). The main etiologic agent of brucellosis in goats is $B$. melitensis. However in certain countries like Brazil where there is no B. melitensis, goats can get infected with B. abortus (Lilenbaum et al., 2007). Camels can be infected by B. abortus and B. melitensis when they are pastured together with infected sheep,goats and cattle. Milk from infected camels represent a major source of infection that is underestimated in the Middle East (Musa et al., 2008). The main etiologic agent for dog brucellosis is B. canis, but sporadic cases of brucellosis in dogs caused by B.abortus, B. suis and B. melitensis have been reported (Acha and Szyfres, 2003).

Nine Brucella species are currently recognized, seven of them that affect terrestrial animals are: $B$. abortus, B. melitensis, B. suis, B. ovis, B. canis, B. neotomae, and B. microti (Scholz et al., 2008) and two that affect marine mammals are: B. ceti and B. pinnipedialis (Foster et al., 2007). The first three species are called classical Brucella and within these species, seven biovars are recognized for $B$. abortus, three for B. melitensis and five for B. suis. The remaining species have not been differentiated in to biovars. The strains of Brucella were named based on the host animal preferentially infected (Verger et al., 1997).

\section{2. 3. Source of infection and mode of transmission}

In humans, consumption of dairy products (especially raw milk, soft cheese, butter and ice cream) is the most important source of infection. It is also possible for raw vegetables and water contaminated through excreta and sometimes consumption of under cooked animal muscle /tissue though the bacterial load is very low (Radostits et al., 2000). Transmission by contact predominates in enzootic areas. Man become infected by handling infected tissues of animals, by close contact with other infected materials, presumably the Brucella enter through skin abrasions or possibly through the intact skin, trans-conjunctival and air born transmission are also indicated. Therefore, human brucellosis is an occupational disease of stockyard, slaughter house workers, bluchers and veterinarians (Walker, 1999).

In animals, the concentration of the bacteria is highest in pregnant uterus. The aborted fetus, placental membranes or fluids, and other uterine discharges are considered as major source of infection. Infected animals also shade organisms in milk which serve as source of infection for the new born. Contaminated feed can spread the infection from infected pasture over long distance during purchasing and selling activities. The disease is transmitted to susceptible animals by ingestion of contaminated feed and water, contact with aborted fetuses, fetal membrane and uterine discharges; infection by inhalation is also possible. The use of infected bull for artificial insemination also poses an important risk and spreads the infection to many herds (Acha and Szyfers, 2001).

\section{3. Pathogenesis and Clinical Signs}

\section{3. 1. Pathogenesis}

Invading Brucella usually localize in the lymph nodes, draining the invasion site, resulting in hyperplasia of lymphoid and reticulo-endothelial tissue and the infiltration of inflammatory cells. 
Survival of the first line of defense by the bacteria results in local infection and the escape of Brucella from the lymph nodes in to the blood. During bacteraemic phase, bones, joints, eyes and brain can be infected, but the bacteria are most frequently isolated from supra-mammary lymph nodes, milk, iliac lymph nodes, spleen and uterus. In bulls, the predilection sites for infection are also the reproductive organs and the associated lymph nodes. During the acute phase of infection, the semen contains large number of Brucella but as the infection becomes chronic, the number of Brucella excreted decreases. However, it may also continue to be excreted for years or just become intermittent (Acha and Szyfres, 2001).

After the Brucella organisms spread through the hematogenous route in females then also reach the placenta and finally to the fetus. The preferential localization to the reproductive tract of the pregnant animal is due to the presence of the allantoic fluid factors that would stimulate the growth of Brucella. Erythritol (four-carbon alcohol) is considered to be one of the factors, which are elevated in the placenta and fetal fluid from about the fifth month of gestation. An initial localization within erythrophagostic trophoblsates of the placentome adjacent to chorio-allntoic membrane results in rupture of the cells and ulceration of the membrane. The damage to placental tissue together with foetal infection and foetal stress inducing maternal hormonal changes may cause abortion (Radostits et al., 2000).

\section{3. 2 Clinical signs}

The primary clinical manifestation of brucellosis in animals is related to the reproductive tract. The most obvious signs in pregnant animals are abortion (usually late abortion), birth of weak calves, lowering of fertility with poor conception rates, retained fetal membrane, endometritis and reduced milk yield. Orchitis and epididymitis are typical signs in males, and hygroma is usually common during chronic infection (Corbel, 1997).

\section{4. Diagnosis and its Limitations}

Clinician must develop a high degree of clinical suspicion based on epidemiological information and history which are critical to making the clinical diagnosis. In all cases a blood sample should be collected from the patient and laboratory testing should be requested as the definite diagnosis of brucellosis is impossible without laboratory confirmation (Young, 1995). A proper and prompt diagnosis is important as the treatment requires specific and prolonged antibiotics. Laboratory tools include isolation and identification of Brucella from clinical samples, detection of antigen, demonstration of genome and demonstration of Brucella specific antibodies (Solara et al., 1997).

\subsubsection{Isolation and identification}

Blood culture provides definite proof of brucellosis but may not provide a positive result for all patients even under ideal conditions (Colmenero et al., 1997). Brucella are relatively slow growing and the culture result may not become available for several days or weeks. They also need special media with carboxyphlic environment. In particular for patients with chronic disease, the sensitivity of culture can be low. Even though blood culture is the method of choice for isolation of the causative agent, specimens need to be obtained early prior to antibiotic administration and need prolonged periods of incubation. In addition, failure to detect the pathogen is a frequent occurrence.The modern automated blood culture systems have somewhat improved the speed of detection but are still too slow to make a rapid diagnosis (Bannatyne et al., 1997). Bone marrow cultures are considered the golden standard for the diagnosis of brucellosis, since the relatively high concentration of Brucella in the reticulo-endothelial system makes it easier to detect the organism. Furthermore, bacterial elimination from the bone marrow is equivalent to microbial eradication. However, in some studies results have not been universally reproducible, suggesting that the bacteraemia is as unpredictable as clinical manifestations especially in human brucellosis (Shehabi et al., 1990).

Identification of Brucella strains is done using standard classification tests, including Gram stain, a modified Ziehl-Neelsen $(\mathrm{ZN})$ stain, growth characteristics, oxidase activity, urease activity, $\mathrm{H}_{2} \mathrm{~S}$ production (four days), dye tolerance such as basic fuchsin (1: 50000 and 1: 100000) and thionin (1:25000, 1:50000 and 1:100000) and seroagglutination. It has been also recommended that Gram stain morphology and modified ZN staining, coupled with the urease test, for rapid identification of Brucella to the level of genus where facilities for further identification are not available. Laboratory 
detection of Brucella and species identification is based largely on culture isolation and phenotypic characterization. This process is lengthy and labour-intensive and has been associated with a heightened risk of laboratory-acquired infections. To surmount these problems, nucleic acid amplification has been explored for the rapid detection and confirmation (Mantur et al., 2006).

\section{4. 2. Antigen and genome detection}

Enzyme linked immune sorbent assay (ELISA): Still now, there is only one report (Al-Shamahy and Wright, 1998) suggesting antigen detection by enzyme-linked immunosorbent assay (ELISA) as an acceptable alternative to blood culture for the diagnosis of brucellosis since sensitivity and specificity are $100 \%$ and $99.2 \%$ respectively. Antigen detection methods are potentially useful but have not been validated. Though co-agglutination has been reported as a technique for antigen detection, there seems to be paucity of published literature.

Polymerase chain reaction (PCR): is fast and can be performed on any clinical specimen. A number of nucleic acid sequences have been targeted for the development of Brucella genus-specific PCR assays, including 16S rRNA, the 16S-23S intergenic spacer region, omp 2 and bcsp31 (Navarro et al., 2002) .Recently, Redkar et al. (2001) described real-time PCR assays for the detection of $B$. abortus, B. melitensis and B. suis biovar1. These PCR assays target the specific integration of IS711 elements within the genome of the respective Brucella species or biovar. Currently, a real-time multiplex PCR assay has been developed for rapid confirmatory identification of Brucella with speciation. The genus, B. abortus and B. melitensis specific primers confirm the organism from isolates. Although in the last few years, PCR is very promising and PCR-based laboratory tests have been proposed, they cannot be considered a routine diagnostic method yet since standardization of extraction methods, infrastructure, equipment and expertise are lacking and a better understanding of the clinical significance of the results is still needed (Navarro et al., 2004).

Molecular characterization techniques are also very useful tools for differentiating Brucella spp. especially follow-up testing of unusual phenotypic results of Brucella isolates. The use of molecular methods in Brucella endemic areas needs to be explored before they can be applied in these areas to diagnose brucellosis.

\section{4. 3. Serologic tests}

The above limitations make serology for antibody detection the most useful tool for the laboratory diagnosis of brucellosis. Antibodies usually begin to appear in the blood at the end of the first week of the disease, IgM appearing first followed by IgG. The serological tests like Rose Bengal Plate Agglutination Test (RBPT), standard tube agglutination test (SAT), Coombs test, immune capture agglutination test, complement fixation test, ELISA, lateral flow assay-a simplified version of ELISA, milk ring test (MRG) are commonly used tests in the diagnosis of brucellosis (Lucero et al., 2003).

Rose bengal plate test (RBPT): is often used as a rapid screening test. The sensitivity is very high (>99\%) but the specificity is disappointingly as low as 68.8\% (Barrsol et al., 2002). However, this is of value as a screening test in high risk rural areas where it is not always possible to perform the tube agglutination titration test. To increase the specificity and the positive predictive value of the RBPT, the test may be applied to a serial dilution (1:2 through 1:64) of the serum sample. The specificity of the test increases when higher dilutions agglutinate and titers of 1:8 or 1:16 and above may be regarded as positive. This approach may result in a lower sensitivity. Whenever possible, a serum that gives a positive result should be confirmed by a more specific test. The RBPT is also of value in the rapid confirmation of neurobrucellosis, arthritis, epididymo-orchitis, hydrocele due to Brucella if the neat is positive in CSF, synovial fluid, testicular fluid /semen and hydrocele fluid respectively (Manture et al., 2006).

Complement fixation test (CFT): detects specific antibodies of the IgM and IgG1 type that fix complement. The CFT is highly specific but it is laborious and requires highly trained personnel as well as suitable laboratory facilities that makes less suitable for use in developing countries. Although its specify is very important for the control and eradication of brucellosis, it may test false negative when antibodies of the IgG2 type hinder complement fixation. The CFT measures more antibodies of the IgG1 than antibodies of the IgM type, as the latter are partially destroyed during 
inactivation Since antibodies of the IgG1 type usually appear after antibodies of the IgM type, control and surveillance for brucellosis is best done by CFT (Buchanan and Faber, 1980).

Serum aglutination test (SAT): developed by Wright and colleagues remains the most popular and yet used worldwide diagnostic tool for the diagnosis of brucellosis because it is easy to perform, does not need expensive equipments and training. SAT measures the total quantity of agglutinating antibodies IgM and IgG (Young, 1991). The quantity of specific IgG is determined by treatment of the serum with $0.05 \mathrm{M} 2$-mercaptoethanol (2ME), which inactivates the agglutinability of IgM. SAT titers above 1:160 are considered diagnostic in conjunction with a compatible clinical presentation. However, in areas of endemic disease, using a titer of 1:320 as cut off may make the test more specific. The differentiation in the type of antibody is also important, as IgG antibodies are considered a better indicator of active infection than IgM and the rapid fall in the level of IgG antibodies is said to be prognostic of successful therapy (Buchanan and Faber, 1980).

Drawbacks of the serum agglutination test include the inability to diagnose $B$. canis infections; the appearance of cross-reactions of class M immunoglobulins with Francisella tularensis, Escherichia coli $\mathrm{O} 116$ and O157, Salmonella urbana, Yersinia enterocolitica O:9, Vibrio cholerae, Xanthomonas maltophilia, and Afipia clevelandensis; and the percentage of cases in which seroconversion does not occur. Lack of seroconversion can be attributed to the performance of tests early in the course of infection, the presence of blocking antibodies, or the so-called "prozone" phenomenon (i.e., the inhibition of agglutination at low dilutions due to an excess of antibodies or to nonspecific serum factors). Some of these shortcomings can be overcome by modifications such as the addition of EDTA, 2-mercaptoethanol, or antihuman globulin (Young, 1991).

Indirect enzyme-linked immune sorbent assay (i-ELISA): typically uses cytoplasmic proteins as antigens. ELISA measures IgM, IgG and IgA, which allows for a better interpretation of the clinical situation. A comparison with the SAT, ELISA yields higher sensitivity and specificity. ELISA is also reported to be the most sensitive test for the diagnosis of central nervous system brucellosis. Among the newer serologic tests, the ELISA appears to be the most sensitive; however, more experience is needed before it replaces the SAT as the test of choice for brucellosis (Almunneef and Memish, 2003).

The rapid and simple assays like Brucella $\operatorname{IgM}$ and $\operatorname{IgG}$ lateral flow and latex agglutination have been developed recently. The sensitivity and specificity of lateral flow assay for culture confirmed brucellosis is $>95 \%$. The sensitivity of the latex agglutination assay was determined to be $89.1 \%$ for the initial serum samples collected for the patients with culture confirmed brucellosis and the specificity was $98.2 \%$. Both these tests are ideal for use as field tests in remote areas and as point of care tests in hospitals and health care centers that lack the expertise and facilities to perform the more demanding classic serologic tests (Abdoel and Smits, 2007).

Generally, all told, antibody profiles do not have specific clinical correlations, and titers often remain high for a protracted period. The asymptomatic patient with an isolated positive titer of class $\mathrm{G}$ and A immunoglobulins, or A immunoglobulin only, has not been adequately studied. Variations of ELISA exist, such as competitive ELISA and sandwich ELISA, which may prove useful as a followup tool (Ariza, 1992).

\section{5. Treatment}

Due to the intracellular localization of Brucella and its ability to adapt to the environmental conditions encountered in its replicative niche e.g. macrophage (Seleem et al., 2008), treatment of domestic animals with antibiotics is not usually successful. Even though, treatment failure and relapse rates are also high in humans, treatment depend on the drug combination of doxycycline with streptomycin which is currently the best therapeutic option with less side effects and less relapses, especially in cases of acute and localized forms of brucellosis (Seleem et al., 2009). Neither streptomycin nor doxycycline alone can prevent multiplication of intracellular Brucella (Shasha et al., 1994). Although the doxycycline-streptomycine regimen is considered as the golden standard treatment, it is less practical because the streptomycin must be administered parentrally for 3 weeks. A combination of doxycycline treatment ( 6 weeks duration) with parentrally administered gentamicin $(5 \mathrm{mg} / \mathrm{kg}$ ) for 7 days is also considered an acceptable alternate regimen (Glynn and Lynn, 2008). 


\section{6. Prevention and Control Measures}

The initial aim of surveillance and control programs is the reduction of infection in the animal populations to reduce the effect of the disease on animal health and production, thus minimizing its impact on human health. An effective control of animal brucellosis requires the following elements: 1) surveillance to identify infected animal herds, 2) prevention of transmission to non-infected animal herds, and 3) eradication of the reservoir to eliminate the sources of infection in order to protect vulnerable animals or herds coupled with measures to prevent re-introduction of the disease (Gwida et al., 2010).

In areas where a brucellosis free status has been established or where such a status is assumed from epidemiological data, the risk of importing the disease by means of animal movement must be protected. Movement of infected animals must be prohibited and import permissions should be given only to certified brucellosis-free farms or areas. This is also true for national and international transport of animal products, in accordance with the general principles and procedures specified in the International Zoo-Sanitary Code of the OIE. This code also describes the testing procedures for animals and quarantine measures (OIE, 2009).

\section{6. 1. Vaccines}

In regions with high prevalence of the disease, the only way of controlling and eradicating this zoonosis is by vaccination of all susceptible hosts and elimination of infected animals (Briones et al., 2001). The most commonly used vaccines against bovine brucellosis are B. abortus strain 19 and the recently approved strain RB51; the latter unlike strain 19 does not interfere with serological diagnoses (Moriyon et al., 2004). Brucella melitensis strain Rev1 although highly infectious to human, is considered as the best vaccine available for the control of ovine and caprine brucellosis, especially when administrated at the standard dose by the conjunctival route. However, the Rev1 vaccine shows a considerable degree of virulence and induces abortions when administered during pregnancy. Also, the antibody response to vaccination cannot be differentiated from the one observed after field infection. The B. melitensis Rev1 vaccine for small ruminants has not been fully evaluated for use in cattle. Brucella abortus vaccines do not effectively protect against $B$. melitensis infection, meaning that bovine $B$. melitensis infections may pose a serious problem even for vaccinated cattle. Vaccination alone will not eradicate Brucella as the immunity produced by Brucella vaccine is not absolute. It is obvious, therefore, that a policy of vaccination is more likely to succeed if combined with good measures of husbandry (Morgan, 1969).

\section{PUBLIC HEALTH AND ECONOMIC IMPORTANCE}

\subsection{Public health Importance}

Brucellosis (especially B. melitensis), remains one of the most common zoonotic diseases worldwide with more than 50,000 human cases reported annually (Gwida et al, 2010). The significance of brucellosis as zonootis has ever increased in recent times, due to the expansion of international commerce in animals and animal products, with increase urbanization, intensive farms and animal products, having nomadic animal husbandry (Bayleyegn, 2007). Despite the advances made in surveillance and control, the prevalence of brucellosis is increasing in many developing countries due to various sanitary, socioeconomic, and political factors (Pappas et al., 2006).

Transmission of brucellosis to humans occurs mainly through the consumption of unpasteurized dairy products especially raw milk, soft cheese, butter, and ice cream, through direct contact with infected animal parts (such as the placenta by inoculation through ruptures of skin and mucous membranes), and through the inhalation of infected aerosolized particles. Brucellosis is an occupational disease in shepherds, abattoir workers, veterinarians, dairy-industry professionals, and personnel in microbiologic laboratories. However, consumption of hard cheese, yogurt, and sour milk are less hazardous, since both propionic and lactic fermentation takes place. Bacterial load in animal muscle tissues is low, but consumption of undercooked traditional delicacies such as liver and spleen has been implicated in human infection (Radostits et al., 2000).

Air borne transmission of brucellosis has been studied in the context of using Brucella as a biologic weapon. In fact, $B$. suis was the first agent contemplated by the U.S. Army as a potential biologic weapon and is still considered in that category. In a hypothetical attack scenario, it was estimated that release of an aerosolized form of Brucella under optimal circumstances for dispersion would 
cause 82,500 cases of brucellosis and 413 fatalities. Cases of laboratory-acquired brucellosis are the perfect examples of airborne spreading of the disease (Ergonul, 2004).

Most common symptoms of brucellosis include undulant fever in which the temperature can vary from $37 \mathrm{C}^{\circ}$ in the morning to $40^{\circ} \mathrm{C}$ in the afternoon; night sweats with peculiar odor, chills and weakness, insomnia, anorexia, headache, arthralgia, constipation, sexual impotence, nervousness and depression (Acha, 2003). Human brucellosis is also known for complications and involvement of internal organs and its symptoms can be very diverse depending on the site of infection and include encephalitis, meningitis, spondylitis, arthritis, endocarditis, orchitis, and prostatitis. Spontaneous abortions, mostly in the first and second trimesters of pregnancy, are seen in pregnant women infected with Brucella (Khan et al., 2001).

Symptoms and signs of brucellosis usually referred as fever of unknown origin can be confused with other diseases including enteric fever, malaria, rheumatic fever, tuberculosis, cholecystitis, thrombophlebitis, fungal infection, autoimmune disease and tumors (Mantur et al., 2007).

Because of these rather non-specific signs, brucellosis is constantly mis-diagnosed as malaria, which is very prevalent in sub Saharan Africa (Maichomo et al., 2009). Direct person-to-person spread of brucellosis is extremely rare. Mothers who are breast-feeding may transmit the infection to their infants and sexual transmission has also been reported (Kato et al., 2007).

\subsection{Economic importance}

Brucellosis causes heavy economic losses in livestock producers. The economic losses arises from abortion, reduced milk production, losses of calves due to abortion and still birth, culling of infected cows, hindering animal export trade of a nation, losses of man-hours, medical costs and government costs incurred for research and eradication program (Georgios et al.,2005).

Although estimates of the costs associated with brucellosis infections remain limited to specific countries, all data suggest that worldwide economic losses due to brucellosis are extensive not only in animal production (culling infected animal, reduced milk, abortion and delayed conception), but also in public health (cost of treatment and productivity loss). For example, official estimates put annual losses due to bovine brucellosis in Latin America at approximately $\$ 600$ million. Although brucellosis eradication programs can be very expensive, they are estimated to save $\$ 7$ for each $\$ 1$ spent on eradication. The USA national brucellosis eradication program, while costing $\$ 3.5$ billion between 1934 and 1997, the cost of reduced milk production and abortion in 1952 alone was \$400 million (Sriranganathan et al., 2009).

\section{CONCluSion AND RECOMmendations}

Brucellosis remains one of the most common livestock and zoonotic diseases worldwide except in those countries where bovine brucellosis has been eradicated. In developing countries brucellosis appears to be more endemic especially in sub-Saharan countries including Ethiopia and its prevalence is increasing due to sanitary, socio-economic and political factors. Existence of brucellosis in a population is detected by identification and isolation on culture, serological tests and PCR based molecular tests although each has limitations. Brucellosis is responsible for abortion, retained fetal membrane, endometritis, orchitis, epidydimitis in animals and undulating fever in humans. The worldwide economic losses due to brucellosis are extensive not only in animal production but also in human health, but surveillance and control measures are not instituted adequately.

Based on this literature review the following points are recommended:

$>$ Further nation-wide and integrated investigations in all production systems of different geographical area should be conducted to have clear image on the magnitude and distribution of the disease.

$>$ Herd and individual animal registration and compensation system should be practiced to have good information, especially if test and slaughter policy is needed to be implemented.

$>$ Public awareness should be raised on the source of infection and method of transmission of the disease to safeguard the public and for the planned control method to be effective

$>$ It is better to produce vaccine which give protection against all Brucella species and biovars which cause bovine brucellosis. 


\section{REFERENCES}

Abdoel, T.H., Smits, H.L. (2007): Rapid latex agglutination test for the serodiagnosis of human brucellosis. Diagn Microbiol Infect Dis., 57:123-128.

Acha,N., Szyfers, B. (2001) :Zonoosis and communicable disease common to man and animals.VolI. Bacteriosis and Mycosis. $3^{\text {rd }}$ edition.Scientific and Technical Pulication.No.580.Washngton,D.C,U.S.A.,Pp.40-62.

Acha, N., Szyfres, B. (2003): Zoonoses and Communicable Diseases Common to Man and Animals, $3^{\text {rd }}$ ed., vol.1.Pan American Health Organization (PAHO), Washington, DC.

Almuneef, M. and Memish, Z.A. (2003): Prevalence of Brucella antibodies after acute brucellosis. $J$ Chemother., 15:148-51.

Al-Shamahy, H.A., Wright, S.G. (1998): Enzyme-linked immunosorbent assay for Brucella antigen detection in human sera. J Med Microbiol., 47:169-72.

Angara,T.E., Ismail, A. A., Agab, H., Saeed, N.S. (2010): Sero-prevalence of bovine brucellosis in Kuku dairy scheme, Khartoum, North Sudan, http://susteh.edu/staff_publicatons/access : Accessed date on September/12/ 2011.

Anonymous (2007): Animal Health Disease Cards. Bovine Brucellosis. http://www.fao.org/ag/againfo/subjects/en/health/diseases-cards/brucellosi-bo.html Accessed date on April/16/2007.

Ariza, J., Pellicer, T., Pallares, R., Foz, A., Gudiol, F. (1992): Specific antibody profile in human brucellosis. Clin Infect Di.s, 14:131-140.

Asmare, K., Asfaw, Y., Gelaye, G., Ayelet, G. (2010): Brucellosis in extensive management system of Zebu cattle in Sidama Zone, Southern Ethiopia. African Journal of Agricultural Research., 5 (3): 257-263.

Bannatyne, R.M., Jackson, M.C. and Memish, Z. (1997): Rapid diagnosis of Brucella bacteremia by using the BACTEC 9240 system. In: J Clin Microbiol., 35 :2673-4.

Barroso, G.P., Rodriguez-Contreras, P.R., Gil, E.B., Maldonado, M.A., Guijarro, H.G., Martin, S.A. (2002): Study of 1,595 brucellosis cases in the Almeria province based on epidemiological data from disease reporting. Rev Clin Esp., $202: 577-82$.

Bayeleyegn, M. (2007): Advanced veterinary public health lecture note. FVM, AAU, Debre- zeit, Ethiopia., Pp.10-32.

Berhe, G., Belihu, K., Asfaw, Y. (2007): Sero-epidemiological investigation of bovine brucellosis in extensive cattle production system of Tigray region of Ethiopia. International Journal of Applied Research in Veterinary Medicine., 5:65-71.

Briones, G., Inon de Iannino, N., Roset, M., Vigliocco, A., Paulo, P.S., Ugalde, R.A. (2001): Brucella abortus cyclic beta-1, 2-glucan mutants have reduced virulence in mice and are defective in intracellular replication in HeLa cells. Infect. Immun., 69: 4528-4535.

Buchanan, T.M., Faber, L.C. (1980): 2-Mercaptoethanol Brucella agglutination test: usefulness for predicting recovery from brucellosis. J. Clin. Microbiol., 11: 691-693.

Chukwu, C.C. (1985):Brucellosis in Africa, Part I. The prevalence. Bull. Anim. Hlth. Prod. Afr., 35:92-98.

Colmenero, J.D., Reguera, J.M., Martos, F., Sanchez-De-Mora, D., Delgado, M., Causse, M. (1997): Complications associated with Brucella melitensis infection: A study of 530 cases. Medicine., 75:195-211.

Corbel, N.J. (1997): Recent advances in brucellosis. J Med microbial., 46:101.

Degefu, H., Mohamud, M., Hailemelekot, M. and Yohannes, M.(2011): Sero prevalence of bovine brucellosis in agro pastoral areas of Jijjiga zone of Somali National Regional State, Eastern Ethiopia. Ethiop. Vet. J., 15 (1): 37-47.

Dinka, H., Chala, R. (2009): Sero prevalence study of bovine brucellosis in pastoral and agropastoral areas of East Showa zone, Oromia Regional State, Ethiopia. American-Eurasian Journal of Agricultural and Environmental Science., 6:508-512.

Ergonul, O., Celikbas, A., Tezeren, D., Guvener, E., Dokuzoguz, B. (2004) : Analysis of risk factors for laboratory-acquired Brucella infections. J. Hosp Infect, 56:223-227. 
FAO (2003): Progress in understanding brucellosis. Vet Record., 641.

Foster, G., Osterman, B.S., Godfroid, J., Jacques, I., Cloeckaert, A. ( 2007): Brucella ceti sp. nov. and Brucella pinnipedialis sp. nov. for Brucella strains with cetaceans and seals as their preferred hosts. Int. J. Syst. Evol. Microbiol., 57: 2688-2693.

Fretin, D., Fauconnier, A., Kohler, S., Halling, S., Leonard, S., Nijskens, C., Ferooz, J., Lestrate, P., Delrue, R.M., Danese, I., Vandenhaute, J., Tibor, A., DeBolle, X., Letesson, J.J. ( 2005): The sheathed flagellum of Brucella melitensis is involved in persistence in a murine model of infection. Cell Microbiol., 7: 687-698.

Georgios, P., Nicolas, A., Mile, B., Epameinonds, T. (2005): Brucellosis. N.Engl. J Med., 352:232536.

Glynn, M. K., Lynn, T.V. (2008): Brucellosis. J. Am. Vet. Med. Assoc., 233: 900-908.

Gwida, M., Al Dahouk, S., Melzer, F., Rösler, U., Neubauer, H., Tomaso, H. (2010): Brucellosis regionally emerging zoonotic disease. Doi: 10.3325/cmj.2010.51.289.

Haileselassie, M. (2008): Sero prevalence study of bovine brucellosis and its public health significance in Western Tigray, FVM, AAU, Ethiopia.

Halling, S.M., Peterson-Burch, B.D., Bricker, B.J., Zuerner, R.L., Qing, Z., Li,L.L., Kapur, V., Alt, D.P., Olsen, S.C. ( 2005): Completion of the genome sequence of Brucella abortus and comparison to the highly similar genomes of Brucella melitensis. I.J. Bacteriol., 187:27152726.

Hilemlekot,M. (2005): Sero prevalence study of brucellosis in cattle and human in Bahr Dar milk shed, FVM, AAU, Debre-zeit, Ethiopia.

Ibrahim, N., Belihu, K., Lobago, F., Bekana, M. (2010): Sero prevalence of bovine brucellosis and its risk factors in Jimma zone of Oromia region, Southwestern Ethiopia. Tropical Animal Health and Production., 42:35-4

Jegerfa, M. (2006): Epidemiology of bovine brucellosis in selected three agro-ecologies in Central Oromia. MSc Thesis, FVM, AAU, Ethiopia.

Kang'ethe, E.K., Ekuttan, C.E., Kimani,V.N., Kiragu, M.W. (2007): Investigations into the prevalence of bovine brucellosis and the risk factors that predispose humans to infection among urban dairy and non-dairy farming households in Dagoretti Division, Nairobi, Kenya. East Afr Med J., 84:96-100.

Kato, Y., Masuda, G., Itoda, I., Imamura, A., Ajisawa, A., Negishi, M. (2007): Brucellosis in a returned traveler and his wife: probable person-to person transmission of Brucella melitensis. $J$. Travel Med., 14: 343-345.

Kebede, T, Ejeta, G., Ameni, G. (2008): Sero prevalence of bovine brucellosis in smallholder dairy farms in central Ethiopia (Wuchale-Jida district). Revue de' Elevage et Medicine Veterinaire des Pays Tropicaux., 159:3-9.

Khan, M.Y., Mah, M.W., Memish, Z.A. ( 2001): Brucellosis in pregnant women. Clin. Infect. Dis., 32:1172-1177.

Lilenbaum, W., De Souza, G.N., Ristow, P., Moreira, M.C., Fraguas, S., Oelemann, W.M. ( 2007): A serological study on Brucella abortus, caprine arthritis-encephalitis virus and Leptospira in dairy goats in Rio de Janeiro. Braz. Vet. J., 173: 408-412.

Lucero, N.E., Escobar, G.I., Ayala, S.M., Silva, P., Nielsen, K. (2003): Fluorescence polarization assay for diagnosis of human brucellosis. J Med Microbiol., 52:883-7.

Maichomo, M.W., Maichomo, J.J., McDermott, S.M., Arimi, P.B., Gathura, T.J., Mugambi, S.M. (2000): Study of brucellosis in a pastoral community and evaluation of the usefulness of clinical signs and symptoms in differentiating it from other flu-like diseases. Afr. J. Health Sci., Pp. $114-119$.

Mantur, B.G., Birada, M.S., Bidri, R.C., Mulimani, M.S., Kariholu, P. (2006): Protean clinical manifestations and diagnostic challenges of human brucellosis in adults: 16 years' experience in an endemic area. J Med Microbiol., 55:897-903.

Mantur, B.G., Amarnath, S.K., Shinde, R.S. ( 2007): Review of clinical and laboratory features of human brucellosis. Indian J. Med. Microbiol., 25: 188-202. 
Matope, D.G., Bhehe, E., Muma, J. B., Land, A., Skjerve, E. (2010): Risk factors for Brucella spp. infection in smallholder household herds. Epidemiol. Infect., 39: 157-164.

McDermott, J.J.and Arimi, S.M. (2002): Brucellosis in Sub-Saharan Africa: epidemiology, control and impact. Veterinary Microbiology., 20:111-134.

Megersa, B., Biffa, D., Niguse, F., Rufael, T., Asmare, K., Skjerve, E. (2011): Cattle brucellosis in traditional livestock husbandry practice in Southern and Eastern Ethiopia, and its zoonotic implication.In:.Acta Veterinaria Scandinavica., 53:24, http://www.actavetscand.com/ content/53/1/24; Accessed date on September 13/2011.

Mensah, G. I., Addo, k. k., Aning, k. G., Nartey, N., Nipah, G. K., Smits, H. L. (2011): Brucella abortus antibodies in raw cow milk collected from Kraals within the Coastal Savannah Zone of Ghana. In: Journal of Basic and Applied Scientific Research., 1(8):942-947.

Morgan, W.J. (1969) :Brucellosis in animals: diagnosis and control.: Proc RSoc Med., 62: 10501052.

Moriyon, I., Grillo, M.J., Monreal, D., Gonzalez, D., Marin, C., Lopez-Goni, I., Mainar-Jaime, R.C., Moreno, E.and Blasco, J.M. (2004): Rough vaccines in animal brucellosis: $\quad$ Structural and genetic basis and present status. Vet. Res., 35: 1-38.

Muma, J. B., Samui, K. L., Siamudaala, V. M., Oloya, J., Matope, G.(2007): Prevalence of antibodies to Brucella spp. and individual risk Factors of Infection in Traditional Cattle, Goats and Sheep Reared in Livestock-Wildlife Interface Areas of Zambia. In: Tropical Animal Health and Production.

Musa, M.T., Eisa, M.Z., El Sanousi, E.M., Abdel Wahab, M.B., Perrett, L. (2008): Brucellosis in camels (Camelus dromedarius) in Darfur, Western Sudan. J. Comp. Pathol., 138: 151-155.

Mustefa, M., Nicoletti, P. (1993): FAO, WHO, OIE guidelines for regional brucellosis control program for the Middle East. Prepared at a workshop held in Amman, Jordan.

Navarro, E., Casao, M. A., Solera, J. (2004): Diagnosis of human brucellosis using PCR. Expert Rev Mol Diagn., 4 :115-23.

Navarro, E., Escribano, J., Fernandez, J., Solera, J. (2002): Comparison of three different PCR methods for detection of Brucella spp in human blood samples. FEMS Immunol Med J.Clin.Microbial.,37:4179-4182.

OIE (2000): Bovine brucellosis Manual of Standards for Diagnostic Tests and Vaccines. $4^{\text {th }} e d$. Paris, France., Pp. 328-345.

Pappas, G., Panagopoulou, P., Christou, L., Akritidis, N. (2006): Brucella as a biological weapon. Cell Mol. Life Sci., 63: 2229-2236.

Pappas, G., Papadimitriou, P., Akritidis, N., Christou, L., Tsianos, E.V. (2006): The new global map of human brucellosis. In: Lancet Infect Dis., 6:91-9.

Radostits, O.M., Gay, C.C., Blood, C. D., Hinchecliff, K.W. (2000): Veterinary Medicine: a text book of the disease of cattle, sheep, pigs and horses, 9th ed. New York W. B. Saunders Company Ltd., Pp.867-882.

Rahman, M, S., Faruk, M.O., Her, M., Kim, J.Y., Kang, S. I., Jung, C. (2011): Prevalence of brucellosis in ruminants in Bangladesh. Veterinarni Medicina Original Paper., 5: 379-385.

Redkar, R., Rose, S., Bricker, B., DelVecchio, V. (2001): Real-time detection of Brucella abortus, Brucella melitensis and Brucella suis. Mol Cell Probes., 15:43-52.

Robinson, A. (2003): Guidelines for coordinated human and animal brucellosis surveillance In: FAO Animal Production and Health Pape., Pp.156.

Schelling, E., Diguimbaye, C., Daoud, S., Nicolet, J., Boerlin, P., Tanner, M., Zinsstag, J. (2003) :Brucellosis and Q-fever sero prevalence of nomadic pastoralists and their livestock in Chad. Preventive Veterinary Medicine., 61: 279 - 293.

Scholz, H.C., Hubalek, Z., Sedlacek, I., Vergnaud, G., Tomaso, H., Al Dahouk, S., Melzer, F., Kampfer, P., Neubauer, H., Cloeckaert, A., Maquart, M., Zygmunt, M.S., Whatmore, A.M., Falsen, E., Bahn, P., Gollner, C., Pfeffer, M., Huber, B., Busse, H.J., Nockler, K. (2008): Brucella microti sp. nov., isolated from the common vole Microtus arvalis. Int. J. Syst. Evol. Microbiol., 58: 375-382. 
Seleem, M.N., Boyle, S. M., Sriranganathan, N. (2008): Brucella: a pathogen without classic virulence genes. Vet. Microbiol., 129, 1-14.

Seleem, M.N., Jain, N., Pothayee, N., Ranjan, A., Riffle, J.S.and Sriranganathan, N. ( 2009): Targeting Brucella melitensis with polymeric nanoparticles containing streptomycin and doxycycline. FEMS Microbiol. Lett., 294: 24-31.

Shafee, M., Rabbani, M., Ali Ahmad, S, A., Ahmad, M. (2011): Prevalence of bovine brucellosis in organized dairy farms, using milk ELISA, in Quetta City, Balochistan, Pakistan. SAGE-Hindawi Access to Research Veterinary Medicine. International Volume 2011, Article ID 358950, 3 pages doi:10.4061/2011/358950.

Shasha, B., Lang, R., Rubinstein, E. (1994): Efficacy of combinations of doxycycline and rifampicin in the therapy of experimental mouse brucellosis. J. Antimicrob. Chemother., 33: 545 -551.

Shehabi, A., Shakir, K., el-Khateeb, M., Qubain, H., Fararjeh, N., Shamat, A. R. (1990): Diagnosis and treatment of 106 cases of human brucellosis. J Infect., 20 :5-10.

Sintaro,T. (1994): The impact of brucellosis on productivity on an improved dairy herds of Chaffa state farm, Ethiopia, MSc Thesis Fuchburg Veterina medizinerei University, Berline.

Solera, J., Martinez-Alfaro, E., Espinosa, A. (1997): Recognition and optimum treatment of brucellosis. Drugs., 53 :245-56.

Sriranganathan, N., Seleem, M.N., Olsen, S.C., Samartino, L.E., What more, A.M., Bricker, B., O'Callaghan, D., Halling, S.M., Crasta, O.R., Wattam, R.A., Purkayastha, A., Sobral, B.W., Snyder, E.E., Williams, K.P., Yu G-, X., Fitch, T.A., Roop, R.M., de Figueiredo, P., Boyle, S.M., He, Y., Tsolis, R.M. (2009): Genome mapping and genomics in animal-associated microbes. In: Brucella Springer (Chapter 1).

Tefera,M. (2006):Study on bovine brucellosis in cattle slaughtered at Addis Ababa and Sululta with focus on occupational hazard, FVM, AAU, Debre-zeit,Ethiopia.

Tolosa,T. (2004): Sero prevalence Study of Bovine Brucellosis and Its Public health Significance in selected sites of Jimma zone Western Ethiopia, FVM, AAU, Debre-zeit, Ethiopia.

Verger, J.M., Grimont, F., Grimont, P.A., Grayon, M. (1997): Taxonomy of the genus Brucella. Ann. Inst. Pasteur Microbiol., 138: 235-238.

Walker, L.R. (1999):Brucella. In: Veterinary Microbiology. Wight, D., Hirsh, C., Yuan Chung Z. (ed.).Blackwell Science., Pp.196-202.

World organization for animal health (2010): Bovine brucellosis. In: Manual of Diagnostic Tests and Vaccines for Terrestrial Animals., 2:31-40.

Yanagi, M., Yamasato, K. (1993): Phylogenetic analysis of the family Rhizobiaceae and related bacteria by sequencing of 16S rRNA gene using PCR and DNA sequence. FEMS Microbiol. Lett., 107: 115-120.

Young, E.J. (1991): Serologic diagnosis of human brucellosis: analysis of 214 cases by agglutination tests and review of the literature. Rev Infect Dis., 13:359-372.

Young, E.J. (1995): An overview of human brucellosis. Clin. Infect. Dis., 21: 283-289. 


\section{AUTHORS' BIOGRAPHY}

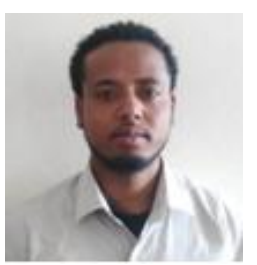

Ashenafi Kiros Wubshet (Msc in Microbiology, Associate researcher at NAHDIC)

Affiliation; NAHDIC (National Animal Health Diagnostic and Investigation Centre, Sebeta Ethiopia)

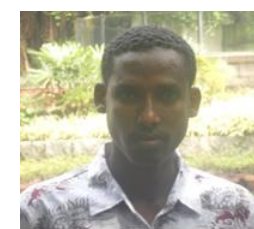

Hagos Asgedom Weldeabyezgi (Msc in Epidemiology, Associate researcher at NAHDIC)

Affiliation; NAHDIC (National Animal Health Diagnostic and Investigation Centre, Sebeta Ethiopia)

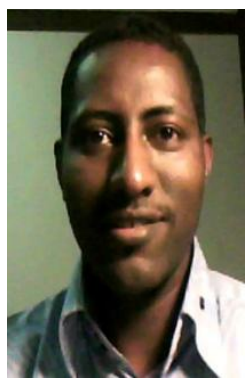

Reta Duguma Abdi ( $\mathrm{PhD}$, College of Veterinary Medicine and Agriculture) Affiliation; Addis Ababa University College of Veterinary Medicine and Agriculture Debreziet, Ethiopia) 